\title{
Pemodelan Segmentasi Mentawai-Pagai: Studi Kasus Gempa Megathrust di Indonesia
}

\author{
Cahya Damayanti ${ }^{1 *}$, Abdul Kadir Yamko ${ }^{1}$, Christian Jacob Souisa ${ }^{1}$, Wempi Barends ${ }^{1}$, Iwan \\ Leonardo Pieter Tia Naroly ${ }^{1}$
}

${ }^{1}$ Pusat Penelitian Laut Dalam - Lembaga IImu Pengetahuan Indonesia, Ambon

Dikirim:
12 November 2020
Direvisi:
17 November 2020
Diterima:
26 November 2020
*Email Korespondensi:
cahyadamayanti.id@gmail.com
() c) () ()

\begin{abstract}
Abstrak: Gempa yang terjadi pada tanggal 25 Oktober di Pulau Mentawai merupakan gempa megathrust segmentasi Mentawai-Pagai. Segmentasi megathrus ini memiliki sejarah gempa yang terjadi sebelumnya yaitu pada tahun 1797 dan 1833. Artikel ini akan membahas review paper tentang model gempa megathrust di segmentasi Mentawai-Pagai yang terdiri dari berbagai aspek kajian, seperti: paleogeodetik, seismologi teleseismik, analisis gempa susulan, mikroatol dan refleksi seismik. Model keretakan yang terjadi di segmentasi Mentawai-Pagai ditemukan di kerak samudera. Energi yang dilepaskan dari gempa megathrust hanya sepertiga dari energi yang tersedia. Kemudian studi lebih lanjut diperlukan untuk memantau prediksi tsunami.
\end{abstract}

Kata kunci: megathrust; Mentawai-Pagai; mikroatol; palegeodetik; teleseismik

Abstract The earthquake that occurred on October 25 on Mentawai Island was a megathrust earthquake for the Mentawai-Pagai segmentation. This megathrus segmentation has a history of earthquakes that occurred previously in 1797 and 1833. This article will discuss a review paper on the megathrust earthquake model in the MentawaiPagai segmentation which consists of various aspects of study, such as: paleogeodetic, teleseismic seismology, aftershock analysis, microatoles and seismic reflection. The rift model that occurs in the Mentawai-Pagai segmentation is found in the oceanic crust. The energy released from a megathrust earthquake is only one-third of the available energy. Then further studies are needed to monitor tsunami predictions..

Keywords: megathrust; Mentawai-Pagai; microateol; palegeodetik, teleseismic

\section{PENDAHULUAN}

Indonesia terletak pada batas pertemuan tiga lempeng-lempeng tektonik besar dunia yang sangat aktif (Rusli dkk., 2012), yaitu lempeng Eurasia, lempeng Pasifik, dan lempeng IndoAustralia serta satu lempeng mikto Filipina. Kondisi tektonik ini menyebabkan Indonesia menjadi rawan bencana gempabumi dan tsunami. Gempa megathrust adalah gempabumi yang terjadi pada zona awal penunjaman (subduksi). lempeng.
Indonesia memiliki 16 segmentasi megathrust yang aktif dan berpotensi menghasilkan gempa besar dan menimbulkan tsunami (Gambar 1), diantaranya adalah: Aceh-Andaman, NiasSimeulue, Kepulauan Batu, Mentawai-Siberut, Mentawai-Pagai, Selat Sunda Banten, Selatan Jawa Barat, Selatan Jawa Tengah-Jawa Timur, Selatan Bali, Selatan NTB, Selatan NTT, Laut Banda Selatan, Laut Banda Utara, Utara Sulawesi,

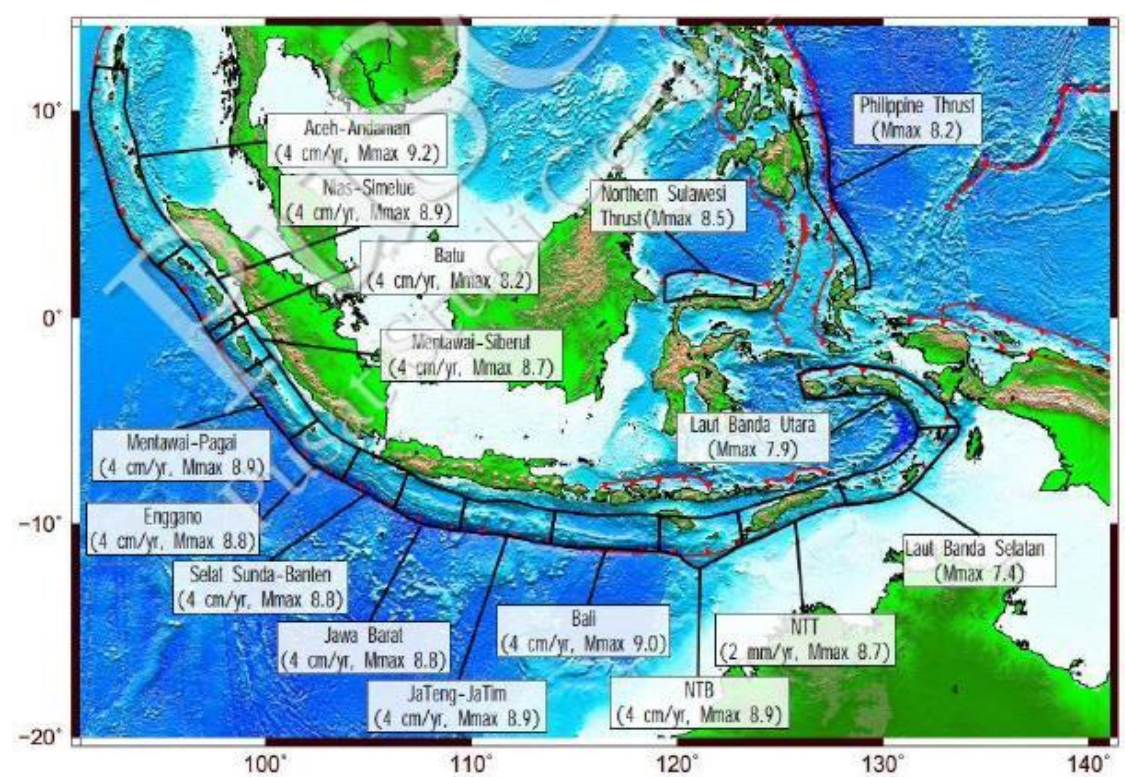

Gambar 1. Segmentasi Megathrust Indonesia (Pusat Gempa Nasional, 2017) 
Subduksi Lempeng Laut Filipia (Pusat Gempa Nasional, 2017). Tulisan ini akan berfokus pada gempa yang terjadi di wilayah segmentasi Mentawai-Pagai.

Sumatera memiliki intensitas kegempaan yang tinggi (Khawiendratama, 2016; Mustafa, 2010). Pada sejarah kegempaan, pada tahun 1797 terjadi gempa dengan magnitudo M 8,3 - 8,7 SR dan pada tahun 1833 M8,9 SR. Kedua gempa ini menyebabkan tsunami besar yang menyapu Sumatera Barat dan Bengkulu. Studi Paleogeodetik menunjukkan bahwa kedua gempa tersebut menyebabkan zona segmentasi Mentawai-Pagai terkunci dan mengumpulkan energi rupture yang besar (Gambar 2).

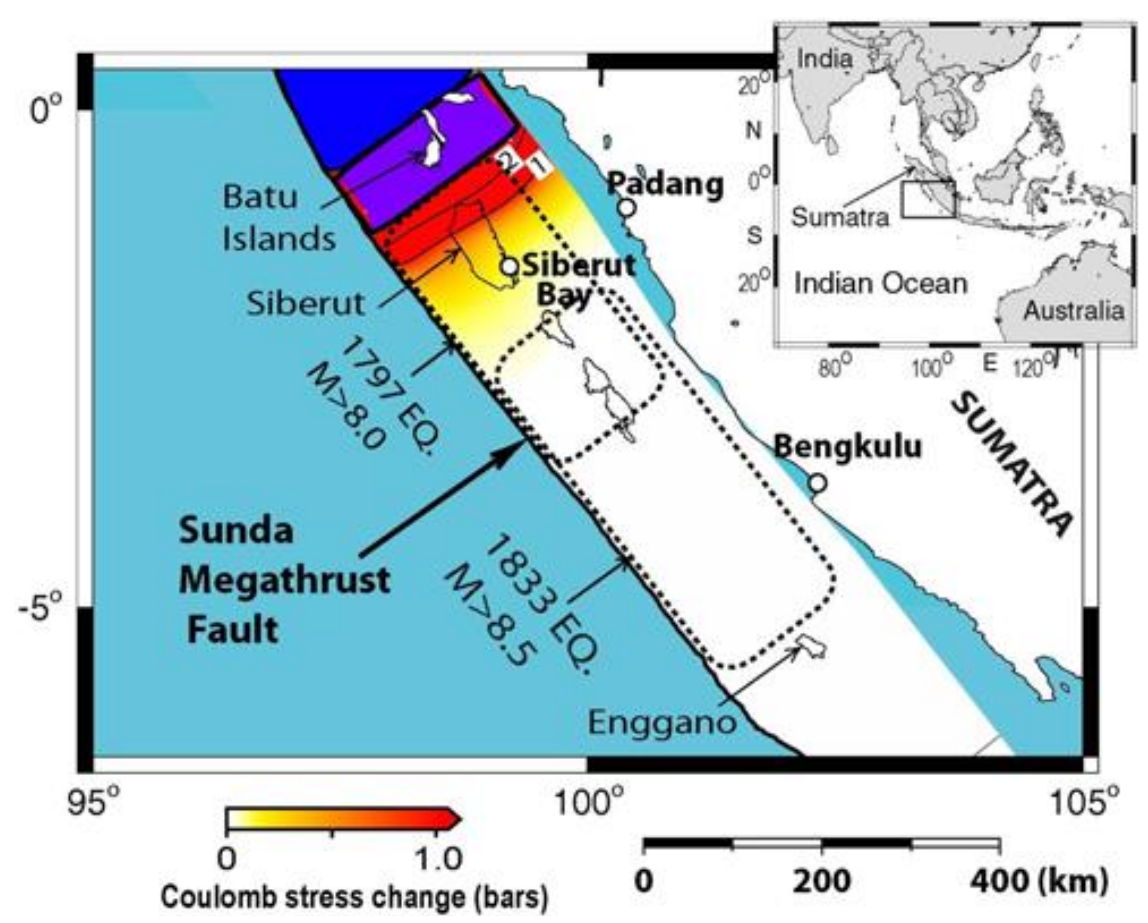

Gambar 2. Data sejarah gempa yang terjadi pada tahun 1797 dan 1833 yang mengunci segmentasi Mentawai-Pagai megathrust (McCloskey dkk., 2007).

Pada tanggal 25 Oktober 2010 pukul 21:42:22 WIB zona segmentasi Mentawai-Pagai terkunci ini akhirnya mengeluarkan energi berupa gempa dengan magnitudo 7,2 (Mw). Posisi gempa terjadi di Kepulauan Mentawai, Sumatera Barat. Pusat gempa berada di lepas pantai barat daya Pulau Pagai dengan koordinat $3,61^{\circ}$ Lintang Selatan dan 99,93 Bujur Timur dengan kedalaman $10 \mathrm{Km}$ di bawah dasar laut (BMKG, 2010). Gempa ini terjadi pada zona awal penunjaman (subduksi) lempeng Indo-Australia terhadap lempeng Eurasia di Samudra India yang dikenal dengan zona megathrust. Gempa ini menyebabkan terjadinya tsunami yang menyebabkan 428 korban jiwa, 74 orang hilang dan 498 orang luka-luka. Selain itu 517 bangunan rusak berat dan 204 rumah rusak ringan. Kerugian yang dialami berkisar $6.8 \mathrm{M}$. Beberapa penelitian telah dilakukan terkait dengan gempa ini di antaranya analisis aftershock, Analisis Proses Rupture dengan Teleseismik, Joint Invertion Teleseismik dan Ground Motion, Analisis Microatoll serta Analisis Seismik Refleksi yang akan dibahas pada review paper ini.

\section{BAHAN DAN METODE PENELITIAN}

Bahan dan metode pada penelitian ini adalah studi literatur yang dilakukan untuk mendapatkan model megathrust segmentasi Mentawai-Pagai dari penelitian sebelumnya.

\section{HASIL DAN PEMBAHASAN \\ 3.1. Analisis Aftershock}

Aftershock adalah gempa susulan atau gempa kecil yang terjadi setelah gempa utama atau mainshock. Hal ini karena saat gempa utama terjadi berarti saat itu lempeng patah, kemudian lempeng akan berusaha mencari posisi paling stabil, maka terjadilah gempa kecil yang disebut aftershock. Analisis aftershock adalah analisis gelombang gempa susulan atau gempa kecil setelah mainshock (Simanjuntak dkk., 2017).

Data mekanisme sumber gempabumi yang digunakan adalah data dari BMKG dan USGS. meliputi lokasi episenter gempabmi (lintang dan bujur), kedalaman sumber gempabumi, panjang dan lebar sesar, strike, dip, dan slip (Setyonegoro dkk., 2012). Gambar 3 menunjukkan perbandingan hasil analisis parameter gempabumi yang terjadi pada tanggal 25 Oktober 2010 di segmentasi Mentawai-Pagai. Terlihat pada gambar bahwa analisis USGS dan BMKG mendekati titik lokasi yang sama. 


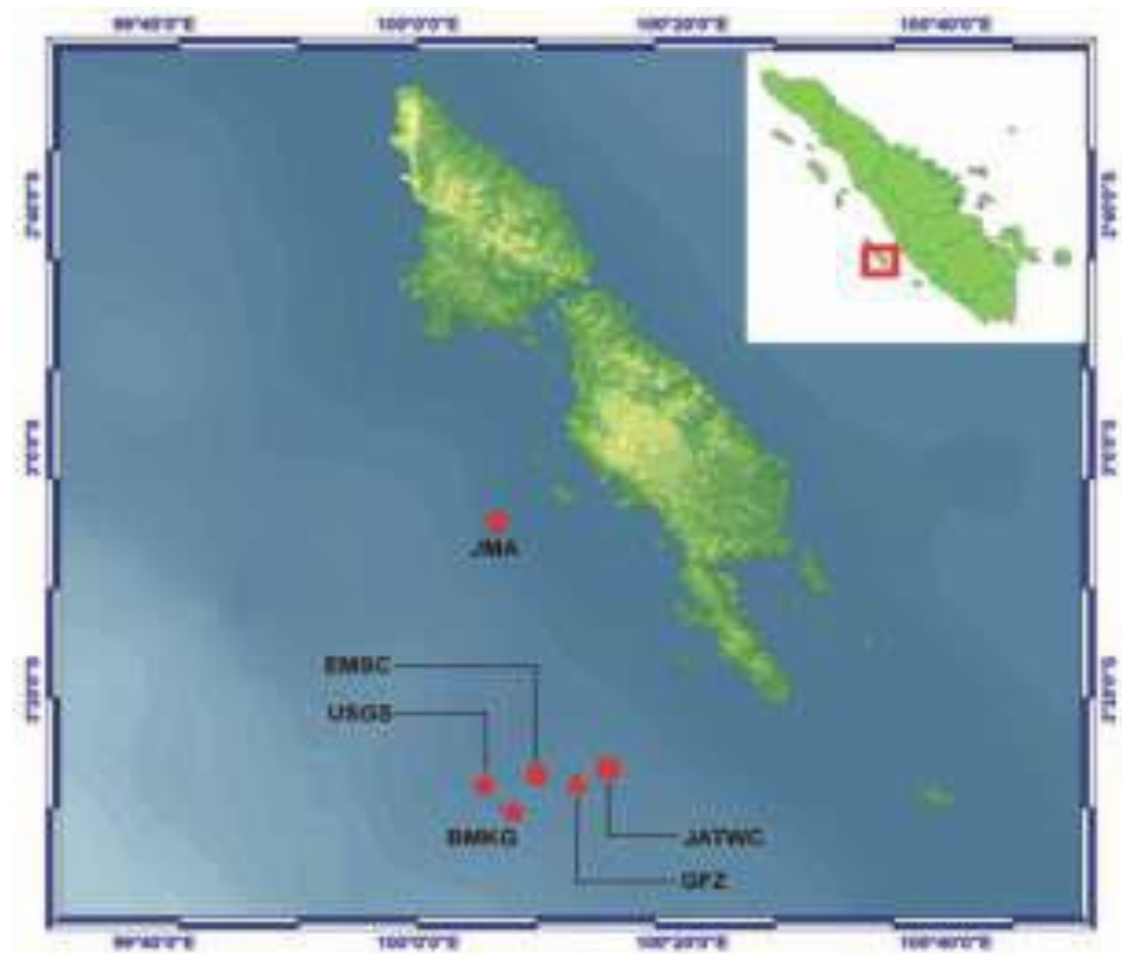

Gambar 3. Perbandingan hasil analisa parameter gempa bumi dari BMKG dan institusi internasional (Setyonegoro dkk., 2012).

Panjang dan lebar sesar dapat ditentukan dari daerah distribusi gempa utama atau mainshock, gempa-gempa kecil sebelum gempa kecil sebelum gempa utama atau foreshock, dan gempa-gempa kecil setelah gempa utama atau aftershock. Berdasarkan data distribusi aftershock diperoleh sesar dengan panjang kurang lebih $180 \mathrm{Km}$, lebar $110 \mathrm{~km}$ dan slip kurang lebih $7 \mathrm{~m}$ (Setyonegoro dkk., 2012).

\subsection{Analisis Proses Rupture dengan Teleseismik}

Lay dkk., (2011) melakukan penelitian analisis sobekan atau rupture gempa Mentawai dilakukan dengan menggunakan data gempa teleseismik, kemudian dianalisis gelombang $\mathrm{P}, \mathrm{SH}$, dan Rayleigh. Model didapatkan melalui metode inversi. Stasiun broadband dari F-Net Jepang (Gambar 4) digunakan untuk membuat analisis

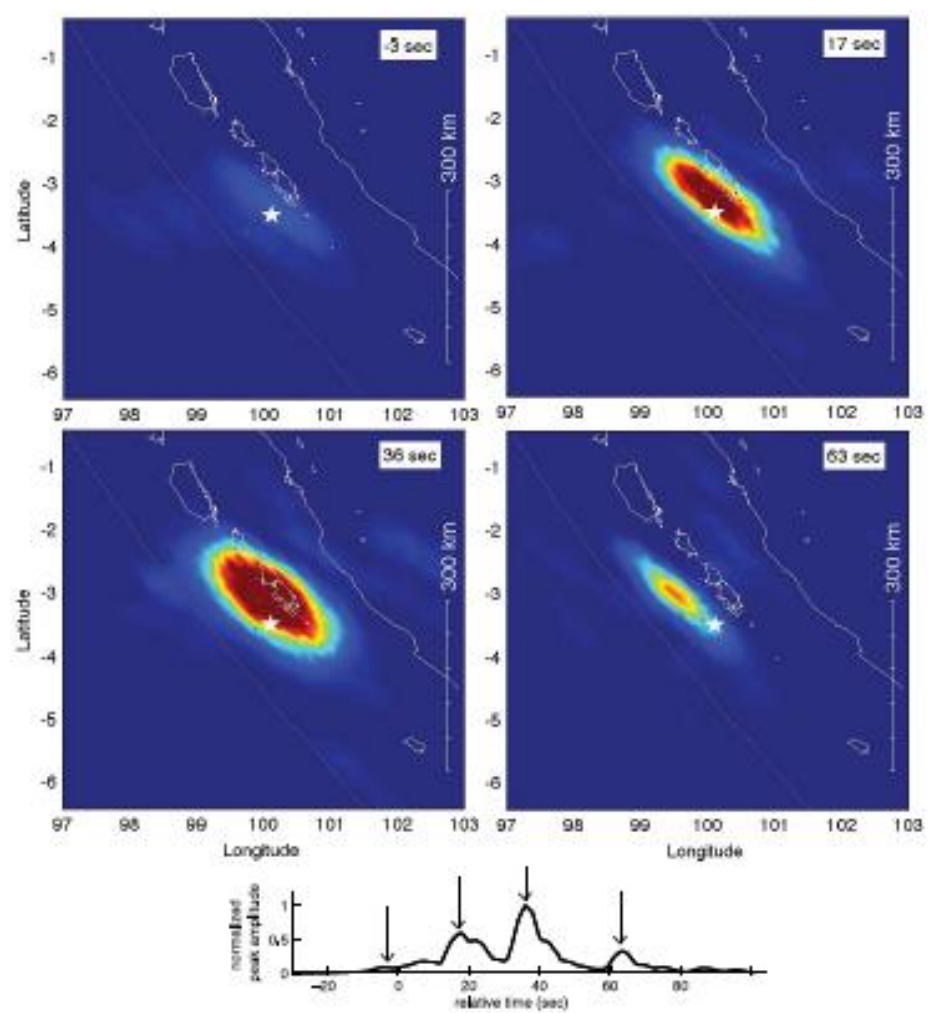

Gambar 4. Analisis proses rupture dengan back-projection (Lay dkk., 2011). 
back-projection untuk melihat seluruh proses terjadinya rupture.

Lay dkk., (2011) mengembangkan model finitesource untuk menjelaskan proses rupture Mentawai dengan menggunakan gelombang teleseismik $p$, sh dan Rayleidh. Hasil inverse menyebutkan bahwa distribusi rupture sampai 100 $\mathrm{Km}$ dengan besar slip 2-3,5 m yang berada di bawah Kepulauan Pagai, dan ini memiliki moment seismik yang rendah tapi memiliki slip yang luas.

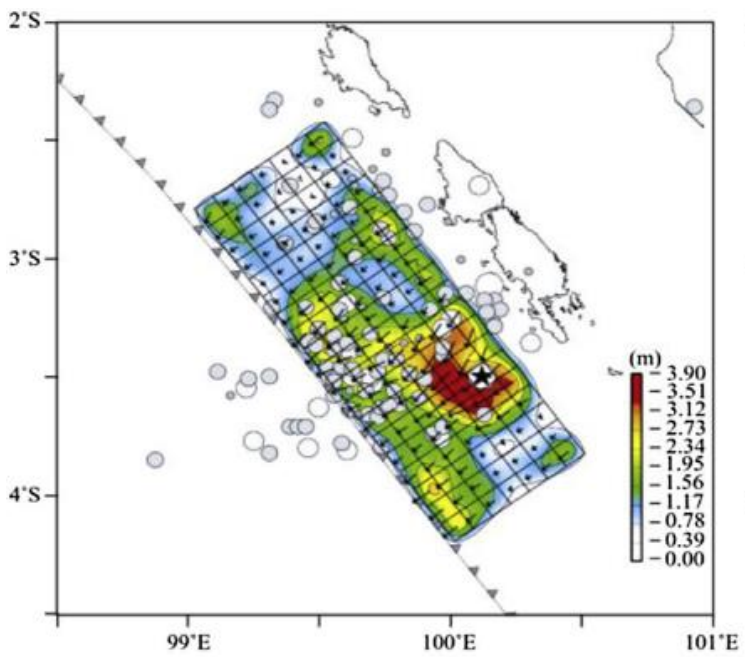

\subsection{Joint Invertion Teleseismik dan Ground Motion}

Lifen dkk., (2015) menggabungkan antara analisis aftershock ground motion dengan teleseismik mendapatkan hasil bahwa gempa Mentawai menyebabkan tsunami yang tidak terduga dan lebih besar dari yang diperkirakan (Gambar 5). Hal ini disebabkan oleh rupture yang terbentuk di sekitar hiposenter menjalar ke arah barat daya dengan slip 3,9 m, kemudian menjalar

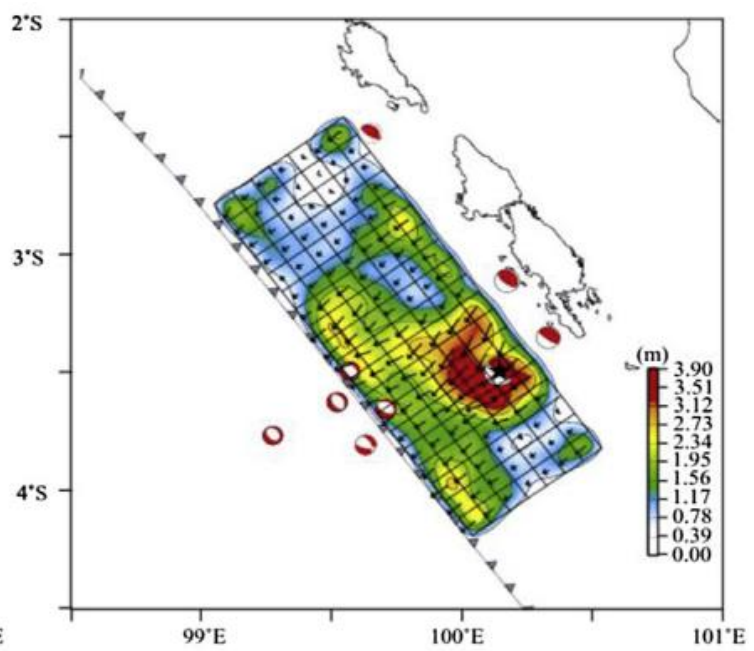

Gambar 5. a) Distribusi slip dan aftershock. b) distribusi slip dan focal mechanism (Lifen dkk., 2015)

kembali ke arah barat laut. Lifen dkk., (2015) menyimpulkan bahwa gempa Mentawai termasuk karakteristik tsunami earthquake karena memiliki durasi pembentukan rupture yang panjang dan menghasilkan tsunami yang lebih besar daripada perkiraan.

\subsection{Analisis Microatoll}

Philibosian dkk., (2012) meneliti microatoll di pulau Pasir Mentawai dengan metode U-Th disequilibrium dating untuk mendapatkan umur kurang lebih dengan kepastian 700 tahun (Gambar 6). Metode U-Th disequilibrium dating adalah metode radiometric dating yang digunakan untuk mengestimasi umur dari material calcium carbonate. Philibosian dkk., (2012) Kemudian merekonstruksi kejadian gempa megathrust dan mendapatkan hasil terjadi dua kali uplift pada tahun 1208 dan 1237, dan diikuti oleh subsidence secara terus menerus $9,5 \mathrm{~mm} /$ tahun. Subsidence ini adalah gerakan permukaan yang bergeser ke bawah relatif terhadap titik datum seperti permukaan laut. Terjadi subsidence yang mendadak pada tahun 1314 diinterpretasikan sebagai pembentukan megathrust. Kemudian dimodelkan megathrust dan dibandingkan dengan hasil yang sekarang. Hasil yang diperoleh ternyata gempa megathrust tahun 2010 ternyata hanya sepertiga dari gempa megathrust yang terbentuk pada tahun 1314
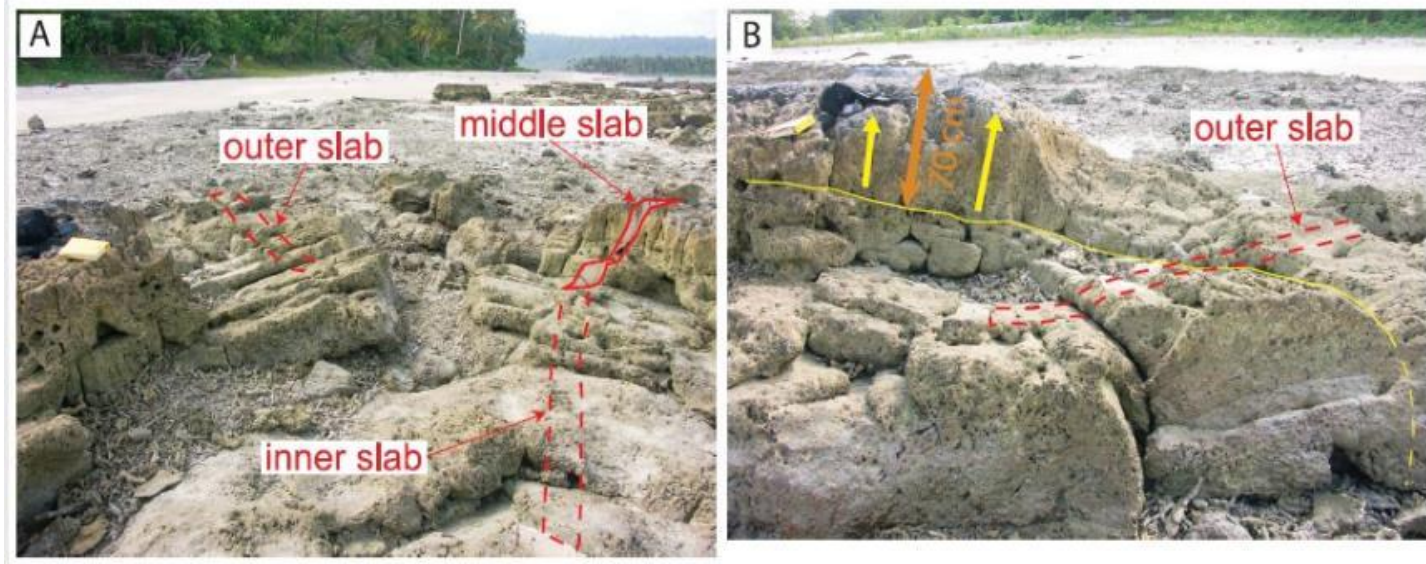

Gambar 6. Foto koral microatoll di Pulau Pasir Mentawai (Philibosian dkk., 2012) 


\subsection{Analisis Seismik Refleksi}

Seismik refleksi termasuk metode geofisika eksplorasi yang menggunakan prinsip seismologi untuk dapat mengetahui sifat-sifat batuan yang ada di bawah permukaan bumi dari respon gelombang seismik refleksi atau gelombang pantul. Singh dkk., (2011) melakukan analisis seismik refleksi dan menjelaskan bahwa Mentawai memiliki struktur Backthrust dengan panjang lebih dari $300 \mathrm{~km}$ dan memiliki strike yang sejajar dengan subduksi Sunda serta dip yang mengarah ke barat. Hasil relokasi gempa menunjukkan ada beberapa gempa di sekitar struktur yang menerus kedalam 20-30 km dan beberapa gempa yang memiliki mekanisme sear naik dengan dip sekitar 60 (Gambar 7).

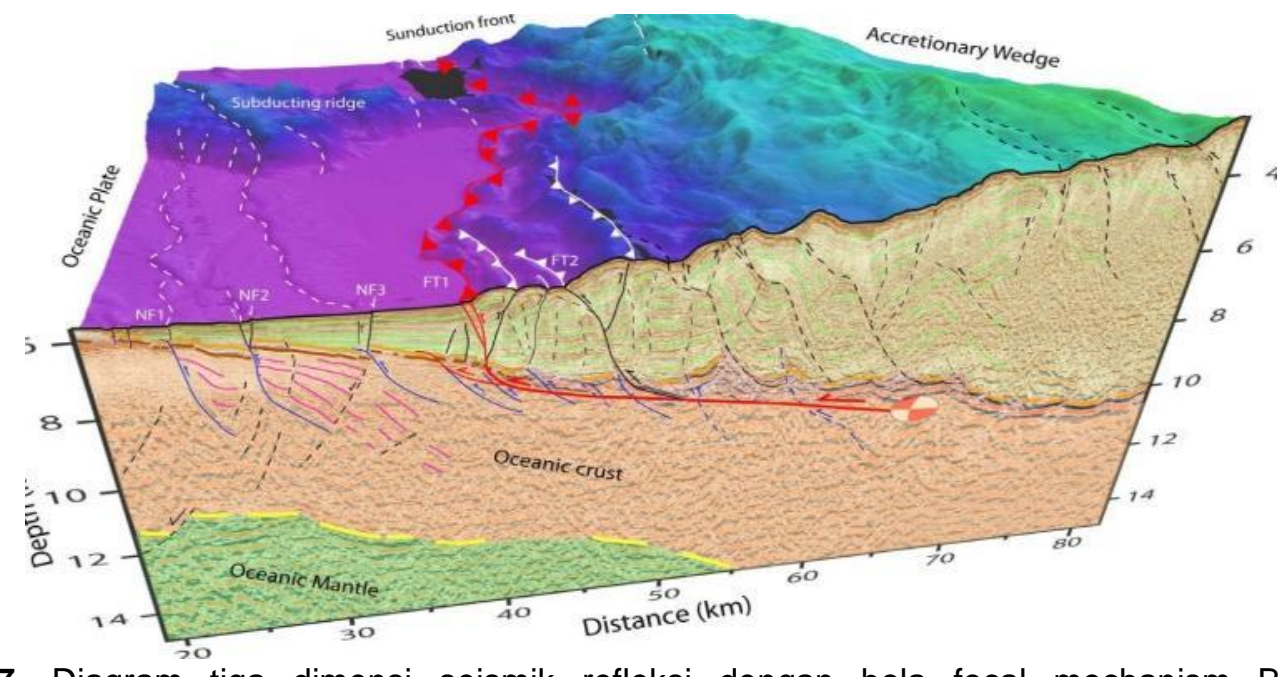

Gambar 7. Diagram tiga dimensi seismik refleksi dengan bola focal mechanism BMKG yang melambangkan hiposenter gempa Mentawai (Singh dkk., 2011).

\section{KESIMPULAN}

Berdasarkan Bentawai-Pagai dapar disimpulkan bahwa tsunami yang disebabkan oleh megathrust segmentasi Mentawai-Pagai memiliki mekanisme gempa tsunamigenik. Tapi karena gelombang tsunami yang datang lebih besar dari yang diperkirakan dan memiliki magnitude gempa yang lebih kecil dan pergerakan rupture yang lebih lambat maka gempa ini termasuk dalam kategori tsunami earthquake.

Gempa megathrust segmentasi MentawaiPagai disebabkan oleh adanya zona yang terkunci dari dua gempa megathrust tahun 1797 dan 1833, sehingga adanya zona gap Mentawai, zona gap ini kembali aktif ketika ada dorongan dari tsunami megathrust segmentasi sumatra andaman atau aceh andaman pada tahun 2004. Berdasarkan data distribusi aftershock dan joint invertion teleseismic diperoleh dimensi rupture panjang kurang lebih $180 \mathrm{~km}$, lebar $110 \mathrm{~km}$ dan slip kurang lebih $7 \mathrm{~m}$.

Model rupture yang terjadi di segmentasi Mentawai-Pagai terdapat di oceanic crust, dan adanya struktur backtrust di timur Mentawai dengan panjang lebih dari $300 \mathrm{~km}$ memiliki strike hampir sejajar dengan subduksi Sunda dan dip yang mengarah ke barat. Energi yang dikeluarkan dari gempa megathrust segmentasi MentawaiPagai tahun 2010 baru sepertiga dari energi yang ada. Maka diperlukan kajian dan monitoring lebih lanjut. Karena jika energi gempa yang dihasilkan lebih besar maka tsunami yang dapat terjadi lebih besar 3 kali lipatnya. Hal ini dibuktikan juga dengan simulasi gempa megathrust tahun 1314 .

\section{UCAPAN TERIMA KASIH}

Kami ucapkan terimakasih kepada para peneliti Megathrust Segmentasi Mentawai-Pagai yang telah melakukan penelitian secara komprehensif sehingga tulisan ini dapat diselesaikan.

\section{DAFTAR PUSTAKA}

BMKG. (2010). Indonesia Tsunami early Warning System. Diakses pada tanggal 22 Mei 2019 dari http://inatews2.bmkg.go.id/new/about inatews.php?urt $=17$

Khawiendratama, B. P. (2016). Analisa Perubahan Kecepatan Pergeseran Titik Akibat Gempa Menggunakan Data SuGar (Sumatran GPS Array). Jurnal Teknik ITS. 5(2), 83-87.

Lay, T., Ammon, C. J., Kanamori, H., Yamazaki, Y., Cheung, K. F., \& Hutko, A. R. (2011). The 25 October 2010 Mentawai tsunami earthquake (Mw 7.8) and the tsunami hazard presented by shallow megathrust ruptures. Geophysical Research Letters. 38, 1-5.

Lifen, Z., Wulina, L., Jingganga, L., \& Quulianga, W. (2015). Estimation of the 2010 Mentawai tsunami earthquake rupture process from joint inversion of teleseismic and strong ground motion data. Geodesy and geodynamics. 6, 180-186

McCloskey, J., Antonioli, A., Piatanesi, A., Sieh, K., \& Steacy, S. (2007). Near-Field Propagation Of Tsunamis From Megathrust Earthquakes. Geophysical Research Letters. 34, 1-5 
Mustafa, B. (2010). Analisis Gempa Nias Dan Gempa Sumatera Barat Dan Kesamaannya Yang Tidak Menimbulkan Tsunami. Jurnal IImu Fisika Universitas Andalas, 2(1), 44-50.

Philibosian, B., Sieh, K., Natawidjaja, D., Chiang, W. H., Shen, C. C., Suwargadi, B. W., Hill, E. M., \& Edwards, R. L. (2011). An ancient shallow slip event on the Mentawai segment of the Sunda Megathrust, Sumatra. Journal Of Geophysical Research, 117, 1-12

Pusat Gempa Nasional. (2017). Peta Sumber dan Bahaya Gempa Indonesia Tahun 2017. Bandung: Pusat Penelitian dan Pengembangan Perumahan dan Permukiman.

Rusli, ljan, \& Rudyanto, A. (2012). Pemodelan Tsunami Sebagai Bahan Mitigasi Bencana Studi Kasus Sumenep dan Kepulauannya. Jurnal Neutrino, 2(2), 164-182.
Setyonegoro, W., Sunardi, B., Sulastri, Nugraha, J., \& Susilanto, P. (2012). The Analysis Of Earthquake Sources On Mentawai Segment (Case Study: 25 Oktober 2010 Earthquake). Jurnal Meteorologi Dan Geofisika. 13(2), 139148.

Simanjuntak, A. V., \& Olymphia, O. (2017). Perbandingan Energi Gempa Bumi Utama dan Susulan (Studi Kasus: Gempa Subduksi Pulau Sumatera dan Jawa). Jurnal Fisika FLUX, 14(1), 19-26.

Singh, S. C., Hananto, N., Mukti, M., Permana, H., Djajadihardja, Y., \& Harjono, H. (2011). Seismic Images Of The Megathrust Rupture During The 25th October 2010 Pagai Earthquake, SW Sumatra: Frontal Rupture And Large Tsunami. Geophysical Research Letters. 38, 1-6. 